\title{
Design, Analysis and Fabrication of Instant water cooler using Thermoelectric Module
}

\author{
Kanchan K. Ingle ${ }^{1} \mid$ Prof. K. N. Wagh ${ }^{1} \mid$ Dr. N.N. Wadaskar ${ }^{1} \mid$ Prof. S. Bhajankar $^{1}$
}

${ }^{1}$ Guru Nanak Institute of Technology, Department of Mechanical Engineering in Heat and Power Engineering, Nagpur, Maharashtra, India

To Cite this Article

Kanchan K. Ingle, Prof. K. N. Wagh, Dr. N.N. Wadaskar and Prof. S. Bhajankar, "Design, Analysis and Fabrication of Instant water cooler using Thermoelectric Module ", International Journal for Modern Trends in Science and Technology, Vol. 06, Issue 07, July 2020, pp.:127-134; https://doi.org/10.46501/IJMTST060720

\section{Article Info}

Received on 17-June-2020, Revised on 28-June-2020, Accepted on 15-July-2020, Published on 22-July-2020.

\section{ABSTRACT}

Hot and cold water is always needed for human being; different systems are used to get hot and cold water. The devices which are available in market for heating and cooling purpose have more cost and size of those systems is more. e.g. refrigerator, electric heater and solar water heater. In this current paper, peltier effect is used to get cold as well as hot water simultaneously with cheapest cost and applicable to used in residential area also. This paper aims toward developing a system which will provide cooling and heating effect simultaneously without moving mechanical parts. Thermoelectric cooling and heating system does not require working fluids. This device can be used to cool water without use of refrigerants. And simultaneously heating can be achieved from the hot side of thermoelectric module to heat the water, this is due to heat absorption and rejection using peltier element. This compact design is very useful in elimination of CFC and it would replace conventional refrigeration system. In this study experimentally Tests were carried out to determine the time taken for the temperature of $250 \mathrm{ml}$ of water in a glass jar to be reduced from $40^{\wedge} \mathrm{oC}$ to below $160 C$. The result shows the cool water and heat water.

KEYWORDS: Thermoelectric cooler element, heat exchanger, peltier element-TEC1-12706, Thermal paste, heat $\operatorname{sink}$

Copyright (C) 2020 International Journal for Modern Trends in Science and Technology

DOI: $\underline{\text { https://doi.org/10.46501/IJMTST060720 }}$

\section{INTRODUCTION}

\section{Basic concept of instant water cooler using} thermoelectric cooler

A thermoelectric module also called as thermoelectric cooler or Peltier cooler, is a semiconductor-based electronics component that functions as a small heat pump, moving heat from one side of the device to the other. Thermoelectric coolers operate according to the Peltier effect. The effect creates a temperature difference by transferring heat between two electrical junctions. A voltage is applied across joined conductors to create an electric current. When the current flows through the junctions of the two conductors, heat is removed at one junction and cooling occurs. Heat is deposited at the other junction. The main application of peltier effect is cooling. However the peltier effect can also be used for heating or control of temperature. In every case, a DC voltage is required. 


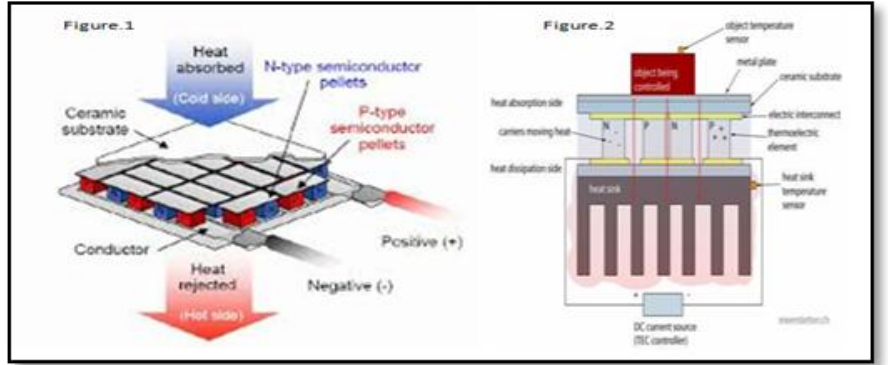

A water dispenser, known as water cooler (if used for cooling only), is a machine that cools or heat up and dispenses water with a refrigeration unit. Water dispensers come in a variety of form factors, ranging from wall mounted to bottle filler water dispenser combination units, to bi-level units and other formats. The instantaneous water cooler employs a bottle or reservoir for storing water to be cooled. No city main inlet connection is required as it is normally used to cool water supplied in 25lit glass bottles, which are placed on top of the unit. Bottled water dispensers typically use 5 or 10 gallon dispensers commonly found on top of the unit. Pressure coolers are subcategory of water dispensers encompassing drinking water fountains and direct-piping water dispensers.

In the instant water cooler water is cooled instantly using thermoelectric module. Thermoelectric element based on peltier effect. The thermoelectric module gives one side heating and another side cooling. For heating side we can use heat sink, heat pipe, etc... and remove the heat towards atmosphere and increases the cooling effect. On the thermoelectric module thermal paste is applied and for cooling side mounted heat exchanger for supplied water from source take inlet of water and another side outlet of cool water. And for another side (heating side) used heat sink or heat pipe, heat exchanger and maintain the temperature difference. By using this process water get cooled instantly and for all this process called as instant water cooler using thermoelectric cooler.

\section{What is Thermoelectric Cooler}

The thermoelectric module called as thermoelectric cooler or peltier element. Thermoelectric cooling is a green alternative to HFC refrigerant that uses a solid state device that acts as a heat pump to transfer heat from one side of the device to another using the Peltier effect. It is made up of numerous pairs of semiconductors enclosed by ceramic wafers. Thermoelectric coolers use direct current power rather than refrigerant gas and a compressor and have no moving parts or complex assemblies.

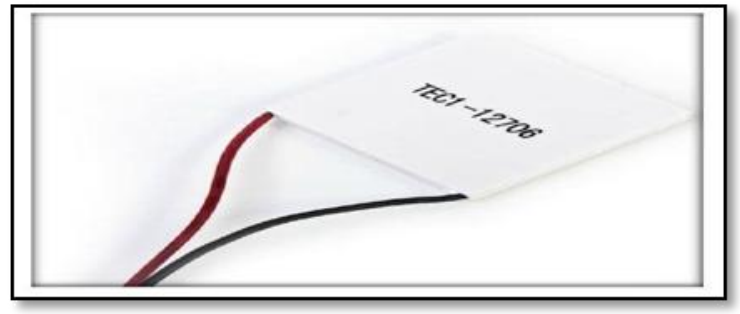

A standard module consists of any number of thermocouples connected in series and sandwiched between two ceramic plates. By applying a current to the module one ceramic plate is heated while the other is cooled. The direction of the current determines which plate is cooled. The number and size of the thermocouples as well as the materials used in the manufacturing determine the cooling capacity. Cooling capacity varies from fractions of Watts up to many hundreds. Different types of TEC modules are single stage, two stage, three stage, four stage, centre hole modules etc...

\section{Principle of Thermoelectric cooler}

The thermoelectric cooler based on these three principle- The Seebeck, Peltier, and Thomson Effects, together with several other phenomena, form the basis of functional thermoelectric modules. The thermoelectric cooler based on peltier effect.

PELTIER EFFECT: The thermoelectric module called as peltier effect. If we modify our thermocouple circuit to obtain the configuration shown in Figure, it will be possible to observe an opposite phenomenon known as the Peltier Effect.

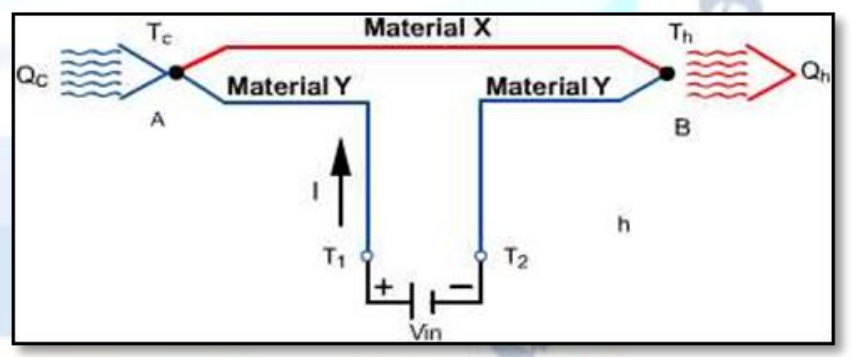

If a voltage (Vin) is applied to terminals $\mathrm{Tl}$ and $\mathrm{T} 2$ an electrical current (I) will flow in the circuit. As a result of the current flow, a slight cooling effect (Qc) will occur at thermocouple junction A where heat is absorbed and a heating effect $(\mathrm{Qh})$ will occur at junction $B$ where heat is expelled. Note that this effect may be reversed whereby a change in the direction of electric current flow will reverse the direction of heat flow. The Peltier effect can be expressed mathematically as: $\mathbf{Q c}$ or $\mathbf{Q h}=\mathbf{p x y} \times \mathbf{x}$ Where, 
pxy is the differential Peltier coefficient between the two materials, $\mathrm{x}$ and $\mathrm{y}$, in volts $\mathrm{I}$ is the electric current flow in amperes Qc, Qh is the rate of cooling and heating, respectively, in watts.

Joule heating, having a magnitude of I $\mathrm{x}$ (where $\mathrm{R}$ is the electrical resistance), also occurs in the conductors as a result of current flow. This Joule heating effect acts in opposition to the Peltier effect and causes a net reduction of the available cooling.

\section{LITERATURE SURVEY}

1)Paper Name: Performance of Thermoelectric Module as a Water Cooler and Water Heater Paper Published by: Mohamad Asmidzam Ahamat\#1, Razali Abidin*, Siti Muzahidah Abdullah\#2

Publishing Year: 2016

This paper presents the total Coefficient of Performance (CoP) of a thermoelectric module in combined heating and cooling modes, obtained through experiments and thermodynamics mathematical model. Thermoelectric module is a solid state heat pump which has a capability to pump heat with the capacity of $100 \mathrm{~W}$ or lower. One of the module surface will acts as a heat sink while another surface of the module rejects heat. This provides an opportunity to utilize both surfaces for cooling and heating applications. The objective of this work was to determine the total CoP of the thermoelectric

module when it was operated in a combination of heating and cooling modes.

2)Paper Name: QUIKCHILL: Thermoelectric water cooler.

Paper Published by: Franz Louie Chua, Brandon Ohara, Rachel Reid, and Bernadette Tong

Publishing Year: 2013

A thermoelectric water chiller was designed to provide a more energy efficient alternative. Implementing the chiller under the sink provides a convenient means to source cold, filtered water, thereby eliminating the need for water and nice dispensers as well as filtering pitchers. The cooling chamber design integrates thermoelectric modules (TEMs), which operate on the Peltier effect to cool filtered water down to $14 \square \mathrm{C}$. The implementation of TEMs reduced current dispenser energy consumption by $82.4 \%$, from $91 \mathrm{~W}$ to $16 \mathrm{~W}$.
3)Paper Name: Comparison of the experimental performance of a thermoelectric refrigerator with a vapour compression refrigerator (VCR).

Paper Published by: Krishpersad Manohar1, Ademola Anthony Adeyanju2

Publishing Year:May-June2014

This paper study shows the experimental comparison between a commercial vapor compression refrigerator and a laboratory built thermoelectric beverage cooler. Tests were carried out to determine the time taken for the temperature of $325 \mathrm{ml}$ of water in a glass jar to be reduced from $32 \mathrm{oC}$ to below $6 \mathrm{oC}$. The result shows that in the freezer compartment of the commercial refrigerator, the temperature of the water decreased linearly with increasing time. However, for the thermoelectric refrigerator, the water temperature decreased exponentially with increasing time.

4)Paper Name: Study and Fabrication of Thermoelectric Air Cooling and Heating System

Paper Published by: Prof. N. B. Totala1, Prof. V. P. Desai2, Rahul K. N. Singh3, Debarshi Gangopadhyay4, Mohd. Salman Mohd. Yaqub5, Nikhil Sharad Jane6 Publishing Year: August 2014

In this paper observed, during the last two decades that the $\mathrm{O} 3$ layer is slowly destroyed because of the refrigerant ( $\mathrm{CFC}$ and $\mathrm{HFC}$ ) used for the refrigeration and air- conditioning purposes. The common refrigerant used is HFC's which are leaked and slowly ascend into the atmosphere. When they reach to $\mathrm{O} 3$ layer they act on $\mathrm{O} 3$ molecules and the layer of $\mathrm{O} 3$ is destroyed. A single molecule of HFC can destroy thousands of $\mathrm{O} 3$ molecules and that's why it has created a threat for the not only to maintain earth eco system stable but also to existence of earth. Even the percentage of HFCs are emitted into the atmosphere compared to $\mathrm{CO} 2$ is negligible but its global warming effect is few thousand times of $\mathrm{CO} 2$. The effect of $100 \mathrm{gm}$ of HFC can destroy 0.5 tons of 03 molecules. These HFCs once destroy $\mathrm{O} 3$ layer; it takes hundreds of years to recover its thickness as it is formed by complex reactions. This is because as HFCs comes in environment, they remain in atmosphere for 18 years. The capacity of HFCs to increase in earth temperature $10 \%$ is contributed by HFC's only. That leads to the emergence of finding an 
alternative of the conventional HVAC system, i.e. thermo-electric cooling and heating system.

\section{PROBLEM DEFINITION}

According to season human needed cold water and hot water. In households refrigerator used for cooling water. And the water takes more than 5 to 6 min for cooling. Space also required more, weight of refrigerator is in between 90 and $181 \mathrm{~kg}$. And the cost of refrigerator is high.

The water dispenser seen in Industry, malls, offices, hospitals, etc... Those water cooler used storage system, And the cooling capacity is more. In household those water cooler not used because it is very costly, and more space required. Hence the thermoelectric element is easily available in market and light weight. By using this element water is cool. And used these water in for household. for It has become commonplace for households to purchase these water dispensers so that you need not have to worry about refilling the water bottles in the fridge. You can as well have your glass of refreshing cold water directly from the tap. Hence, The instant water cooler is required less space, compact in size, less time require for cooling water, more efficient.

\section{OBJECTIVES}

The objective of my project are :

1) To eliminate the emission of $\mathrm{CFC}$ (Chlorofluorocarbon) from water dispensers, this could ultimately reduce global warming and also reduce power consumption.

2) To provide a system with less maintenance and a long life time.

3) Minimization of cost of the system.

4) To reduce the size and weight of the system.

5) Increasing the cooling rate with maintaining temperature difference.

6) $200 \mathrm{ml}$ of water cool in 30 seconds.

\section{v. DESIGN AND CALCULATION}

\section{Known data:}

When I used the thermoelectric cooler according to their capacity requirement is calculated

Calculate current and power for cooling $200 \mathrm{ml}$ of water in 30sec

According to Thermoelectric element TEC1-12706 properties are: Specification of thermoelectric element
Specification TEC1-12706

\begin{tabular}{|l|c|c|}
\hline & Minimum & Maximum \\
\hline $\begin{array}{l}\text { Hot Side } \\
\text { Temperature }(\stackrel{\circ}{ } \mathrm{C})\end{array}$ & 25 & 50 \\
\hline Qmax (Watts) & 50 & 57 \\
\hline Delta Tmax (으) & 66 & 75 \\
\hline Imax (Amps) & 6.4 & 6.4 \\
\hline Vmax (Volts) & 14.4 & 16.4 \\
\hline $\begin{array}{l}\text { Module Resistance } \\
\text { (Ohms) }\end{array}$ & 1.98 & 2.30 \\
\hline
\end{tabular}

The dimension of TEC1-12706 element is

$L^{*} B=40 * 40 \mathrm{~mm}$, height $=3.6 \mathrm{~mm}$, weight $=30 \mathrm{gm}$

\section{1) Power calculation}

Power $(\mathrm{P})=$ Current $(\mathrm{I})^{*}$ (voltage) $\mathrm{V}$

$\mathrm{P}=$ Heat $(\mathrm{Q}) /$ Time $(\mathrm{T})$ unit in watt

$\mathbf{P}=\mathbf{Q} / \mathbf{3 0}$ in watt $\quad . . . . . . . . .$. equation (1)

\section{2) Heat Calculation}

$\mathrm{Q}=$ mass $(\mathrm{m})^{*}$ Specific heat of water $(\mathrm{Cpw})^{*}(\mathrm{Th}-\mathrm{Tc})$ unit in joules

According to summer temperature inside in room as Consider, $\mathrm{Th}=40$ degree celcius

By experimental testing on 10 people and requirement of cooling water temperature for drinking is, $\mathrm{Tc}=16$ degree celcius.

Where, $\mathrm{Th}=$ hot side temperature and $\mathrm{Tc}=$ Cold side Temperature

Mass of water or amount of water cool, $\mathrm{m}=200 \mathrm{ml}=200 \mathrm{gm}=0.20 \mathrm{~kg}$

Time, $\mathrm{t}=30$ second

$\mathrm{Q}=0.2 * 4.18 *(40-16)$

$Q=20092.8 J o u l e$

$\mathrm{P}=\mathrm{q} / \mathrm{t}$ Joule $/ \mathrm{s}$ or watt

$\mathrm{P}=20092.8 / 30$

\section{$P=669.76$ watt (assume 700watt)}

Heat rejected at hot side is given by

$\mathrm{Qh}=\mathrm{mCp}(\mathrm{Th}-\mathrm{Tc})$

$\mathrm{Qh}=Q=20092.8 \mathrm{Joule}$

$\mathrm{Qc}=\mathrm{Qh}-\mathrm{P}$

$Q c=19392.8$ joule

Voltage Of $12 \mathrm{v}$ From Peltier Element and power supply $=700$ watt

Then,

$\mathrm{P}=\mathrm{I}^{*} \mathrm{~V}$

$\mathrm{I}=\mathrm{P} / \mathrm{V}=669.76 / 12$

I=58.33 Amp (assume 60amp)

Hence,

Power Supply $=700$ watt

Current $=60 \mathrm{Amp}$ 
Hence, for water cooling of $200 \mathrm{ml}$ in 30 sec for that power required 700watt and current is 60 amp.

The cooling of water is depend upon the power, current and extraction of heat from the surface of heating.

3) Design the Heat Exchanger

According to the thermoelectric cooler dimension length, width and height of the heat exchanger is decided.

The thickness of the strip will be $0.05 \mathrm{~cm}$

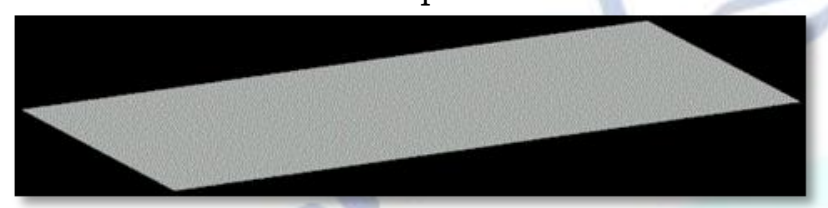

\section{Fig. 23 Thin sheet}

For one heat exchanger dimensions are,

Length *width*height $=12 * 4 * 0.05 \mathrm{~cm}$

Inside the length of $12 \mathrm{~cm}$ number of strips will be 24 number.

Boarder dimensions are

$12 * 0.5^{*} 0.05 \mathrm{~cm}$ for four walls

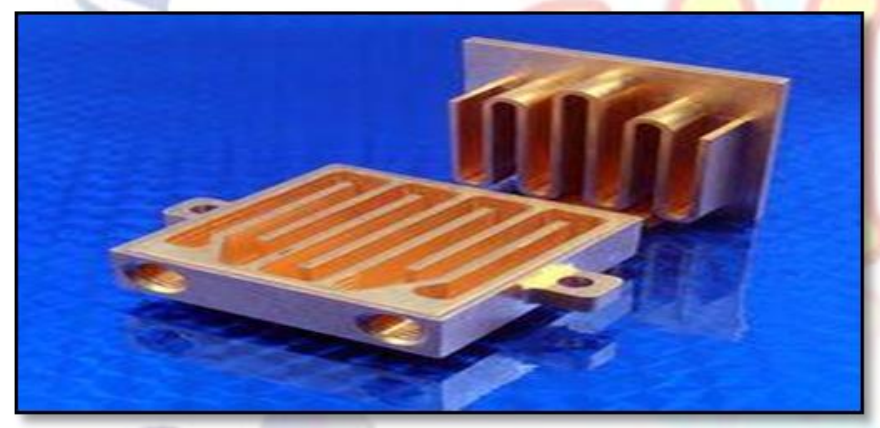

Fig. Heat Exchanger

\section{EXPERIMENTAL SETUP}

\section{Methodology Planned}

\section{For thermoelectric cooler Arrangement}

If the thermoelectric element arranged in parallel, In parallel arrangement current is constant and voltage is increases, like $\mathrm{v} 1+\mathrm{v} 2+\mathrm{v} 3+\ldots .$. so on, According to $\mathrm{P}=\mathrm{I}^{*} \mathrm{~V}$, required of thermoelectric module will be 10 elements.

If the thermoelectric element arranged in series, In the series arrangement voltage is constant and current is increases, like $\mathrm{I} 1+\mathrm{I} 2+\mathrm{I} 3+\ldots . .$. so on, According to $\mathrm{P}=\mathrm{I}^{*} \mathrm{~V}$, the required of thermoelectric module will be 3 elements with less space than in parallel arrangement.

\section{Fig.thermoelectric series arrangenment}

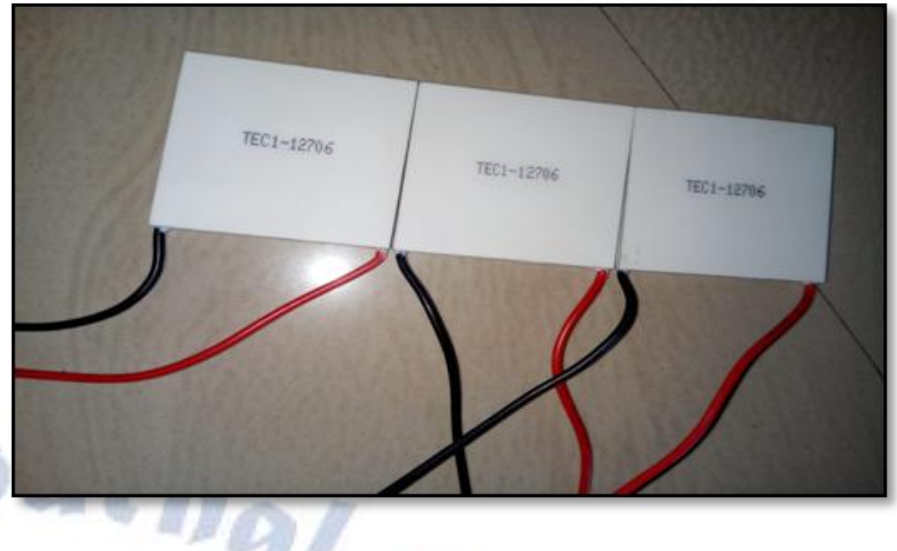

Hence I selected series arrangement with 3 thermoelectric elements.

After selecting 3 thermoelectric cooler TEC1-12706, how to arrange is important, because if I have more than 2 elements and I placed randomly so the output gets only one is heating or either cooling. Hence firstly check the arrangement of thermoelectric cooler. After electrically checking for 3 elements so, the thermoelectric element arranged in series with the one side cooling all and another side all is heating.

\section{Heat Exchanger Arrangement}

Firstly, I decided to arrange the heat exchanger both heating and cooling water inlet both side but the arrangement is get complicated, and difficult to pump. But is opposite side arrangement water is flowing properly no need to pump and easy to arranged. Easy to mount on wall iunstant water cooler using the heat exchanger arrangement.

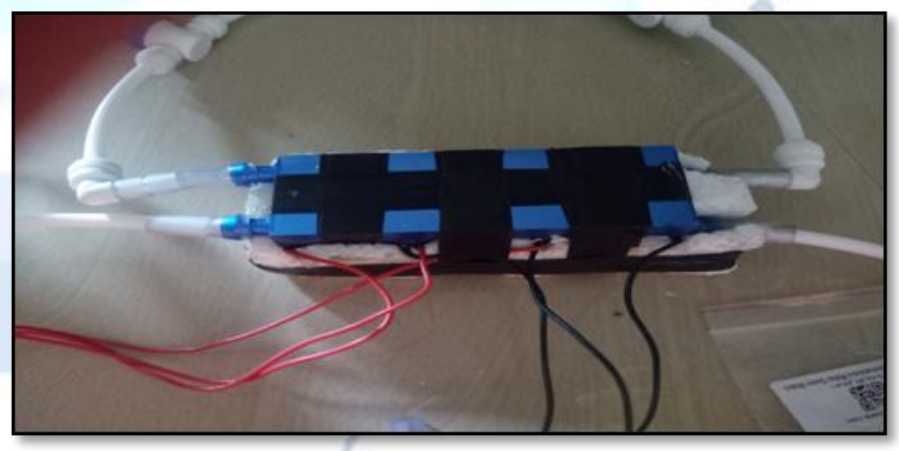

Fig. Heat exchanger arrangement

\section{Working principle}

Working of $\mathrm{TE}$ water cooler is same as that of normal cooler. In normal water cooler water cooled by using refrigerant but in this $\mathrm{TE}$ cooler water is cooled by thermoelectric cooler element. Inside the thermoelectric cooler semiconductor arranged when we gives the power supply so the electrons moves positive to negative and vice versa and by this process one side heating and another side cooling is generated. The thermoelectric cooler is mostly used for the cooling. 
Experimental setup shown in Fig. consists of the following components: 1 . Thermo Electric Module, 2. Heat pipe, 3. Insulation material, 4. Thermal paste, 5. Insulation tape, 6. Valve, 7. Pipe, 8. Power supply.

Fig. Block diagram of instant water cooler

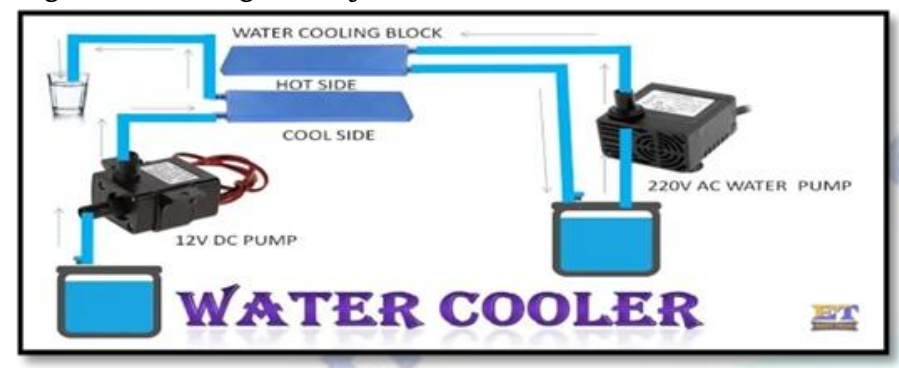

The thermoelectric cooler element or peltier element TEC1-12706 and apply both side thermal paste properly. One heat exchanger mount on cold side and another side (heating side) also mount heat exchanger. After that insulated the assembly part using thermal insulated tape because heat is not transfer from one side to another. Insulation used for cold side because heat is not dissipated to atmosphere. Material of insulation is used thermocoal. Connect the pipe hot and cold side, one side get input and another side get output. On the both side of inlet hot and cold used valve for controlling flow one side high and another side low for required water cooling is get fast, and for analysis purpose also, used temperature meter for checking water temperature and then, connect the power supply and take the reading.

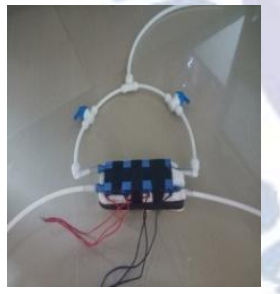

Fig. Experiment setup

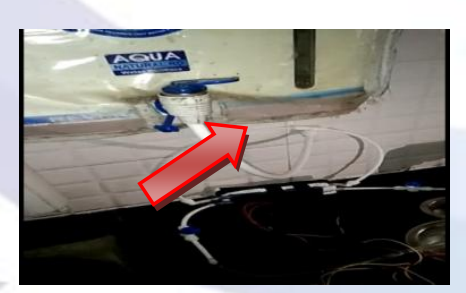

fig. Source of water
When power supply is on thermoelectric cooling element one side heated and another side gets cooled. By using conduction process the heat transfer in the heat exchanger water is flowing inside of pipe the baffle plate is working as obstacle and helps for increasing cooling rate. From the source water is takes and provides inside the heat exchanger both the side through pipe and by using baffle plate water helps to circulate and took sometimes to cool water with simultaneously heating side also same process follows. When temperature difference is less cooling rate is more.
Heat is removed more in terms of hot water and cooling water efficiency increases.

One of the biggest drawbacks is hot water and cold water get simultaneously. This system design for cold water if you not required hot water but you get with cold water hence this hot water used for cooking, and if you not need so preserved in thermos box.

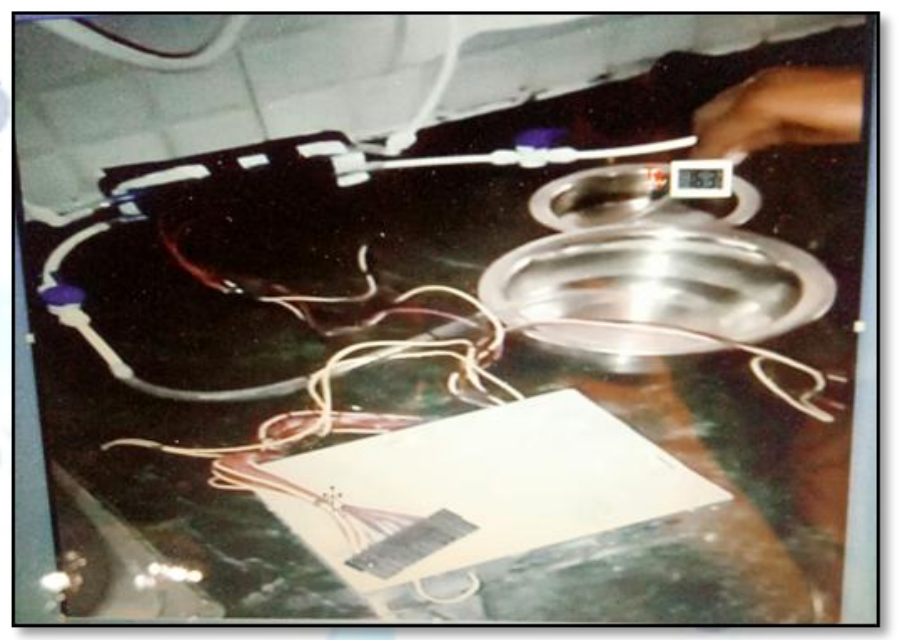

Fig. Experimental setup for instant cold water

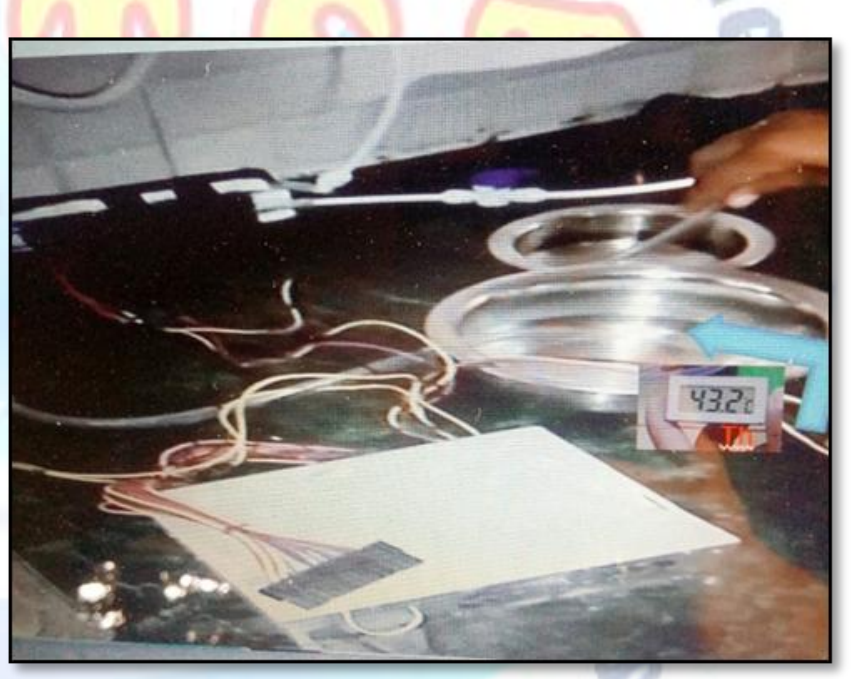

Fig. Experimental setup for instant hot water

\section{Advantages}

- Total weight of the system is less.

- Less space required.

- Cost of the system is less.

- Noiseless.

- More efficient.

- Easy to manufacture.

\section{Disadvantages}

- High cost for a given cooling capacity and poor power efficiency. 
- When open the valve for cold side, get both water simultaneously if you not required.

\section{SCOPE}

- The thermoelectric cooler element used for generating electricity like in thermal power plant.

- Improve rate of refrigeration and coefficient of performance at minimum cost of operation.

- The power supply to a thermoelectric cooler can be obtained from a thermoelectric generator or solar energy.

- The thermoelectric element used in cooling : 1) Medical field, Industrial area, etc..

\section{RESUlts}

\begin{tabular}{|c|c|c|c|}
\hline Sr. No. & Time in sec & Cold water temperature in oC & Hot water temperature in oC \\
\hline 1. & 0 & 27 & 27 \\
\hline 2. & 5 & 25 & 29 \\
\hline 3. & 10 & 23 & 31 \\
\hline 4. & 15 & 19 & 34 \\
\hline 5. & 20 & 16 & 36 \\
\hline 6. & 25 & 15 & 37 \\
\hline 7. & 30 & 14 & 38 \\
\hline
\end{tabular}

\section{Graph}

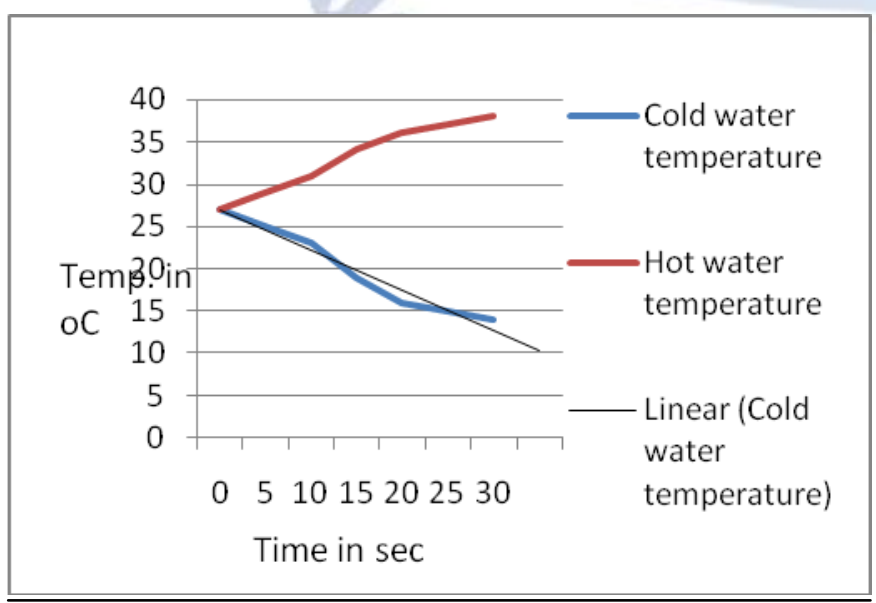

\section{Conclusion}

The thermoelectric cooling and heating system for water cooler and heater (Water dispenser) is working with satisfactory conditions. This system produces hot and cold water simultaneously. It is a solid state heat transfer system which requires no use of refrigerants When open the valve for cold side, get both water simultaneously if you not required.

hence there is no emission of CFC. In the paper arrangement is effective and maintain the temperature difference with these minimize the cost.

And the objective of the project $250 \mathrm{ml}$ of water cools in $30 \mathrm{sec}$ is satisfactory.

\section{REFERENCES}

[1] Kaseb S., El-hairy G, Electronics Cooling, Mechanical Power Engineering Department, Faculty of Engineering, Cairo University, Egypt .

[2] H. Sofrata, "Heat rejection alternatives for thermoelectric refrigerators," Energy Conversion and Management, vol. 37, pp. 269-280, 1996

[3] Enescu D, Virjoghe EO, A review on thermoelectric cooling parameters and performance, Renewable and Sustainable Energy Reviews , 2014, 38:903-916.

[4] Goldsmith, H.J. , Introduction to thermoelectricity, Springer-Verlag Berlin Heidelberg 2010.

[5] D. Zhao, G. Tan, A review of thermoelectric cooling: materials, modeling and applications, Applied Thermal Engineering (2014), doi: 10.1016/ j.applthermaleng.2014.01.074.

[6] S. Riffat, X. ma, Improving the coefficient of performance of thermoelectric cooling systems, international journal of energy research Int. J. Energy Res. 2004; 28:753-768.

[7] J. Vian, D. Astrain, "Development of a heat exchanger for the cold side of a thermoelectric module", Applied Thermal Engineering 28 (2008) 1514-1521.

[8] https://www.electronicscooling.com/2003/05/anintrodu ction-to-pulsating-heat-pipes/

[9] "Intermediate Temperature Heat Pipe Life Tests and Analyses". www.1act.com.

[10] "Heat Pipes", Fifth Edition, D. A. Reay, P.A. Kew.

[11] M A Ahamat \& M. J. Tierney, Timewise temperature control with heat metering using a thermoelectric module, Applied Thermal Engineering 31 (2011) 1421-1426

[12] M A Ahamat \& M. J. Tierney, Calorimetric assessment of adsorbents bonded to metal surfaces: Application to Type A silica gel bonded to aluminium, Applied Thermal Engineering 40 (2012), 258-266

[13] Mohamad A. Ahamat \& Michael J. Tierney. Calorimetric Assessment of Rates of Desorption, Heat Transfer Engineering, Volume 37, Issue 7-8, 2016

[14] Nizar Ahammed, Lazarus Godson Asirvatham, Somchai Wongwises. Thermoelectric cooling of electronic devices with nanofluid in a multiport minichannel heat exchanger, Experimental Thermal and Fluid Science, Volume 74, June 2016, Pages 81-90

[15] Chein R, Huang G. Thermoelectric cooler application in electronic cooling. Applied Thermal Engineering 2004;24 :2207-17. 
[16] Putra N, Yanuar, Iskandar FN. Application of nanofluids to a heat pipe liquid- block and the thermoelectric cooling of electronic equipment. Exp Therm Fluid Sci 2011; 35:1274-81.

[17] Performance of Thermoelectric Module as a Water Cooler and Water Heater Mohamad Asmidzam Ahamat\#1, Razali Abidin*, Siti Muzahidah Abdullah\#2 \# HVACR Section, Universiti Kuala Lumpur, Malaysia France Institute, Bandar Baru Bangi,Selangor, Malaysia. E-mail: 1asmidzam@unikl.edu.my, 2muzahidah@unikl.edu.my

[18] Design and Fabrication of a Peltier Operated Portable Air Cooling System

[19] Nilesh Varkute, Akshay Chalke, Deepak Ailani, Ritesh Gogade, Ajay Babaria Mechanical Engineering Department, F.C.R.I.T Vashi, Navi Mumbai, Maharashtra, India

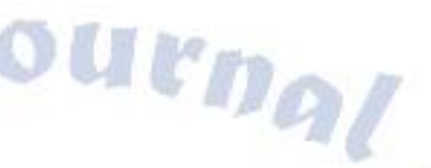

